\title{
Low Level Laser Therapy in Orthodontics: An Update
}

\author{
Madhurima Nanda, Dinesh Kumar Bagga, Sakshi Tiwari, \\ Aartika Singh, Prashant Kumar Shahi \\ Department of Orthodontics \& Dentofacial Orthopedics, School of Dental \\ Sciences, Sharda University, Greater Noida, Uttar Pradesh, India.
}

\begin{abstract}
There has been an increase in demand for esthetic treatment in recent years. In spite of the benefits associated with the Orthodontic treatment in improving esthetics, the increased duration of treatment and the discomfort associated has led to the treatment rejection by patients. As a result, various methods have been explored to reduce the pain associated with the treatment also to enhance the speed of Orthodontic treatment .Lasers are being used widely in dentistry for many years. Recently low-level laser therapy has gained attention in orthodontics owing to its wide area of application like in orthodontic pain management, acceleration of orthodontic tooth movement and bone regeneration. This article aims to discuss about the applications, effectiveness and clinical feasibility of Low - level laser therapy in Orthodontics.
\end{abstract}

KEY WORDS: LOW LEVEL LASER THERAPY (LLLT), ORTHODONTIC TOOTH MOVEMENT (OTM), ORTHODONTIC PAIN, LASERS.

\section{INTRODUCTION}

With the spending times and evolving ways of life, an ever-increasing number of patients are getting aware of their appearance because of which there is an expanded interest for orthodontic treatment. Despite the increased interest for orthodontic treatment with time, the pain and discomfort associated with the orthodontic treatment along with the longer treatment duration have been significant reasons leading to refusal and discontinuation of orthodontic treatment. The pain during orthodontic tooth movement mainly occurs after orthodontic force application creating a zone of Compression and tension further resulting in a cascade of reactions occurring at molecular level.

\section{ARTICLE INFORMATION}

Received 28th Oct 2020 Accepted after revision 17th Dec 2020 Print ISSN: 0974-6455 Online ISSN: 2321-4007 CODEN: BBRCBA

Thomson Reuters ISI Web of Science Clarivate Analytics USA and Crossref Indexed Journal

\section{Clarivate
Analytics}

NAAS Journal Score 2020 (4.31)

A Society of Science and Nature Publication,

Bhopal India 2020. All rights reserved.

Online Contents Available at: http//www.bbrc.in/

Doi: http://dx.doi.org/10.21786/bbrc/13.15/26
Various methods have been advocated for the management of Orthodontic pain like analgesics, bite wafers, chewing gum, transcutaneous nerve stimulation and vibratory stimulations. NSAIDS are considered effective in controlling pain, however the side effects associated with them, forestall their broad use. There is little evidence in literature supporting the clinical applicability of other alternatives. Laser therapy, especially low-level laser therapy (LLLT) has received increased attention in recent years as of late alternative to reduce the pain and discomfort associated with the orthodontic procedure.

History of Lasers: The first Laser was introduced by an American physicist, Dr. Theodore Maiman utilizing a ruby precious stone in 1960 . Soon from that point forward, Goldman brought Lasers into the clinical field. He additionally reported the role of ruby lasers on dental caries and furthermore their impact on teeth in his resulting examines. Bell laboratories developed the neodymium doped yttrium aluminum garnet (Nd:YAG) laser and carbon dioxide (CO2) laser in 1964 and their use in oral tissues was investigated. The early commercial laser, Pulsed Nd:YAG was created by Myers and Myers in dentistry in 1989. From that point forward the potential utilization of Lasers has been explored in dentistry. 
Various studies are being led to investigate the clinical ease of use of Lasers in different fields of Dentistry.

Basic Theory of Lasers: Laser stands for Light Amplification by Stimulated Emission of Radiation. It works on the principle of spontaneous emission based on Einstein's theory. An excited atom absorbs a quantum of energy and releases photons. These photons travel as a coherent wave and cause further emission of identical photons resulting in amplification and hence production of Laser beam.

Components of Lasers: Laser light is a monochromatic light consisting of a single wavelength of light. It has following three components: A lasing material or an active medium consisting of a gas, a crystal, or a solidstate semiconductor, energy source or a pump source which adds energy to the active medium such as, a flashlamp strobe device, an electrical current, laser radiation and the optical cavity or resonator consisting of 2 mirrors or reflectors to act as the feedback mechanism. As the pumping mechanism supplies energy the laser system, energy is pumped into an active medium present within an optical resonator, resulting in spontaneous emission of photons resulting in amplification.

Properties of Laser: The three unique properties of Laser are Monochromacity: As compared to conventional light the wavelength of light emitted is of only one broad wavelength or colour; Collimation: Laser light has a constant direction, size and shape as all the photons emitted have ;Coherency: All the light waves are moving together in a similar manner.

Laser delivery systems and Emission modes: In dental lasers, the different types of Laser light delivery systems are via a Glass fiberoptic cable in which a glass fiber cable is encased in a sheath .This can be used in both contact and non contact fashion; ND: YAG lasers, diode and Erbium lasers are the different types using this delivery system. Hollow tube- like waveguide, or articulated arm or hand pieces: The beam is delivered in a non-contact system like in $\mathrm{CO} 2$ lasers.

The various types of emission modes are Continuous wave in which the laser is emitted at a constant power level like Argon, Diode and C02; Gated pulsed mode in which alteration of the laser energy occurs from time to time like Diode and C02; Free running pulse mode in which energy is released for a short period followed by a longer duration in which the Laser is off, like $\mathrm{Nd}$ : YAG, Erbium and H:YAG

Tissue interactions: As the Laser hits the target tissues, there are four types of interactions that can take place depending on the optical properties of that tissue. The first is the Transmission which occurs when the Laser passes through the tissues without affecting the target tissue. This effect depends on the wavelength of the Laser. The second effect is the Reflection which occurs when the beam redirects from the tissue surface resulting in no effect. The third effect is the Scattering that transfers the heat produced by Laser beam to the adjacent tissues resulting in no biological effect on target tissues. The fourth effect is the absorption which is the desirable effect of Lasers and depends on its wavelength and emission mode and tissue characteristics.

Biological Effects on Tissues: There are different photo biological effects of dental lasers: Photo thermal effect of Laser energy is when the light energy is converted into heat. This thermal effect depends on the degree of temperature rise and also on the water content of tissues. Surgical incision and excision, ablation and hemostasis occur as a result of this effect. Photochemical effects are produced when when the Lasers result in chemical reactions such as curing of the composite resin. The photoacoustic affects of Laser produces a Shock wave resulting in explosion of tissues and creation of crater. This effect is beneficial for procedures on dental hard tissues. Lasers also have a bio stimulating effect, which is useful in pain relief, wound healing and antiinflammatory effect.

Applications in Orthodontics: The lasers which are used in dentistry are of two types- Low level Laser therapy (LLLT), also known as Cold Laser performing under wavelength of 500mW like Diode and Helium Neon and High Intensity Laser therapy, known as Surgical Lasers owing to their tissue cutting capacity like CO2, Nd:YAG, Erbium and diode lasers of applications of LLLT include acceleration of tooth movement, reduction of pain caused during orthodontic procedures and bone regeneration following expansion.

According to the studies carried out in Literature, lowlevel Laser therapy seems to be a promising alternative in pain control and acceleration of tooth movement. The energy output of LLLT is low enough so as not to cause the temperature of the treated tissues to rise above $36.5^{\circ} \mathrm{C}$ or normal body temperature, as a result of which LLT's mainly show non-thermal and biostimulatory effects. The mechanism of laser analgesia is attributed to multiple actions, including elevating body surface temperature, creating a nerve block, inhibiting pain inducing substances through the increased local circulation reducing the oxidative stress and increasing the production of ATP. LLLTs also have also shown an increase in osteoblastic and osteoclastic activity explaining their role in bone remodeling and acceleration of tooth movement. This article reviews the use of LLLT in the field of Orthodontics.

Pain Control during Orthodontic tooth movement: Pain can be experienced by the patient in varying amount is different procedures like separators placement, initial wire placement, reactivation. The fear of pain and discomfort associated with these procedures can prevent patients from beginning orthodontic treatment or can lead to poor compliance in those already undergoing the treatment. Different strategies for controlling pain have been suggested among which NSAIDS are still the main option. However, due to the adverse effects and interference with orthodontic tooth movement (OTM) 
associated with the use of NSAIDS, the LLLT is explored not only for pain control but also for accelerating orthodontic tooth movement.

A lot of research has been done to explore the effectiveness of LLLT in pain control in Orthodontics. The exact mechanism of pain control is still not known but different hypothesis have been proposed for the same. The possible mechanisms are: inhibition of cyclooxenase-2 mRNA expression, inhibition of nerve depolarization, reactivation of enzymes targeting pain-inductive-factors, production of ATP, reduction of prostaglandins (peripheral level) and affecting the synthesis and metabolism of endorphins (central level). The various low-level laser therapy (LLLT) laser described in literature for pain control in orthodontics are Helium Neon Laser, Carbon Dioxide (CO2) laser and the diode Gallium aluminium arsenic (GaA1As) lasers. All these lasers have varying wavelengths.

Diode Lasers, also known as semi conductive lasers, are the most widely used lasers. They can penetrate deep into the tissues, hence controlling the pain based on their wavelength which varies from 600-1000nm. The two commonly used diode lasers used for pain management are Gallium Aluminium, Arsenic ( GaA1As) with a wavelength of 780-790 $\mathrm{nm}$ and GaAIP laser with a wavelength of 630-700nm. Numerous studies have been done to support their role and efficacy in pain management and the results are conflicting. The effect on pain has been evaluated during different phases of Orthodontic treatment like separators placement, banding, placement of initial wire, occlusal functions, canine retractions and reactivations.

Elastic separators are placed so as to create space between adjacent teeth to aid in for band placement. This procedure can result in initiation of pain starting from within $30 \mathrm{sec}$ after separators placement to up to 24 hours. The analgesic effect of low level laser therapy after separators placement and wire reactivations has been documented in literature. However, the results are conflicting with few studies that do not support the role of low level laser therapies in pain control. The variation in results in different studies can be because of the difference in the methodologies, the different study designs, the variations in the technical specifications of different laser systems and also the methods of applications.

There exists a wide variation in the wavelength of lasers used, the mode, and the type of study, number of application of lasers, the pain assessment scale and the optimal dosage. Regarding the laser wavelength, it was found that a greater analgesic capacity was seen in studies using a wavelength between 800 and $830 \mathrm{~nm}$ as compared to studies using Lasers in a wavelength of 904$940 \mathrm{~nm}$. When different modes were compared, it was reported by some researchers that there is greater tissue penetration and repair with pulsed modes as compared to continuous modes . Effect on pain with Single vs. Double or multiple applications of Lasers has also been studied.
In most of the studies, LLLT has shown to be effective for pain reductions with single applications by most of the studies. Few studies have shown effectiveness of LLLT with only two or more applications.

There has been a wide variation in the dosage used in studies ranging from 5 to $35 \mathrm{~J} / \mathrm{cm} 2$. Bjordal et al had used a dose of $7.5 \mathrm{~J} / \mathrm{cm} 2$. Farias et al and Abtahi et al used 6 $\mathrm{J} / \mathrm{cm} 2$ but there were difference in their results because of the different wavelengths used. So, energy density can be one of the factors in determining the effectiveness but not the only parameter in determining the success. Variations are also found in the type of study designs. The method of pain evaluation, the methods to elicit pain and pain assessment scale can also vary depending on the type of occlusal forces applied. Systematic reviews and Meta analysis conducted to study the effect of Lasers on pain suggest that in spite of the heterogeneity and the methodologies bias in the study, low level laser therapy is found to be beneficial in alleviating orthodontic pain. However, future studies with better study designs are required to establish an effective LLLT protocol so as to consider low-level Laser therapy as a routine method in alleviating pain during orthodontic procedures.

Accelerating Orthodontic tooth movement: Prolonged duration of 2 to 3 years associated with orthodontic treatment can be a major reason for denial by patients in spite of the benefits associated with the treatment. Not only the duration but also the iatrogenic effects associated with longer treatment time such as root resorption, decalcification, caries etc. has led to a search for less invasive techniques like LLLT to fasten the orthodontic tooth movement. The rate of tooth movement depends on the periodontal and alveolar bone remodeling in response to force by alteration of blood flow, release of chemical messengers and recruitment of osteoblasts and osteoclasts. Various in vivo studies have shown that LLLT has a bio-modulating effect such as increased collagen synthesis, increased proliferation of fibroblasts, differentiation and activation of osteoblasts and osteoclasts, increased ATP levels, activation of enzymes involved in healing and repair, neovascularization thereby leading to accelerated orthodontic tooth movement (OTM).

At the molecular level, increased levels of receptor activator of nuclear factor- $\kappa \mathrm{B}$ (RANK and RANKL) and the macrophage colony-stimulating M_CSF on the compression sides and increased expression of Type I collagen, fibronectin and osteopontin on the tension side are suggestive of increased Osteoclastogenesis and bone formation on the compression and tension sides respectively.

Many animal and human studies have found LLLT's to be effective in accelerating tooth movement. The first human study to evaluate the effect of LLLT on OTM was conducted by Cruz et al in 2004 in which they used a Galium Aluminium Arsenic GaAlAS diode laser with a wavelength of $780 \mathrm{~nm}$ and an output power of $20 \mathrm{~mW}$ applied 4 times a month (0n day 0, 3 , 7, 14 , and 21 days 
) and found that the increase in rate of tooth movement by $34 \%$.Several other studies conducted have also shown an increase in the rate of tooth movement when diode lasers were used in the range of 780-810nm , with almost similar output power, time and irradiation intervals. In a study conducted by Limpanichkul(2006), they used GaAlAS Diode lasers and found that the LLLT had no effect on canine retraction and it was concluded from the study that it could be because of the low energy density $(25 \mathrm{~J} / \mathrm{cm} 2)$ used at the surface level because of which there was neither any stimulatory nor inhibitory effects on the tooth movement.

Few recent studies have also shown conflicting results showing no effect of LLLT on tooth movement..In the study conducted by Madhavi et al,57 no effect was found on the tooth movement which was attributed to the low sample size used in the study and also the duration of the study which was only 4 weeks. Another recent triple blind split study by Mistry et al has shown nonsignificant findings with LLLT and have concluded that no change in rate of tooth movement was found on application of LLLT. The nonsignificant results in this study could have been because of the difference in energy dosage and the frequency of applications. It has been suggested by few authors that there has to be balance between power density and the time so as to achieve optimal results. The authors in this study have a used an energy dose of $13 \mathrm{~J}$ per session which is an intermediate of the doses used in earlier studies and also the frequency of application is less as compared to the previous studies. The difference in the outcomes of the studies conducted can be related to the sample size, the laser type, wavelength, power, total energy, the energy density used, irradiation time and also on factors like tissue thickness, composition and the mode of contact of lasers with tissues. Therefore, the future research should aim in a direction so as to determine an optimal dosage for low level laser therapy.

Bone regeneration: Studies have been done to evaluate the role of Low-level laser therapy on bone regeneration. The reason for relapse which occurs can be attributed to insufficient bone regeneration along the mid-palatal suture following maxillary expansion using orthopedic forces. LLLT stimulates new bone formation by increased osteogenesis, angiogenesis, and increased fibroblast proliferation. As a result of this, the stability of the bone expansion procedures increases.

According to the Randomized Controlled trials on humans evaluating the effects of low level laser therapy on bone healing following rapid maxillary expansion ,it was found that immediate bone regeneration and healing after midpalatal suture expansion was enhanced with the use of low level laser therapy inspite of the variations in studies like the application protocol, the wavelength, the dosage used ,the points of irradiation .[59-62] Histological analysis of the irradiated bone also shows an increased production of osteoblasts, osteoclasts, fibroblasts, collagen, increase in the vascular proliferation, growth factors and synthesis of new bone matrix. As per the recent systematic reviews carried out by Skondra et al. LLLT can be considered as an effective intervention for stimulating immediate bone regeneration and healing after midpalatal suture expansion, however stronger evidence is required for the clinical applicability of LLLT in bone regeneration.

\section{CONCLUSION}

Low level laser treatment can be utilized in orthodontics to reduce the pain and discomfort, quicken the treatment procedure consequently reducing the duration of treatment and furthermore in increasing the stability of the bone regenerating procedures. Many randomized controlled trials conducted to assess the effects of LLLT on pain, support the usefulness of Low level laser therapy in Orthodontics but due to the heterogeneity of the studies especially due to the different parameters used, results are conflicting .So, newer studies with stronger evidence are required so that a standard protocol can be developed for application of Lasers in Clinical practice.

\section{REFERENCES}

Abtahi SM, Mousavi SA, Shafaee H, Tanbakuchi B (2013) Effect of low-level laser therapy on dental pain induced by separator force in orthodontic treatment. Dent Res J Isfahan 10(5):647-651

Al Sayed Al Sayed Hasan MMA, Sultan K, Hamadah 0 . Low-level laser therapy effectiveness in accelerating orthodontic tooth movement: A randomized controlled clinical trial Angle Orthod. 2017;87(4):499-504.

Albertini R, Aimbire F, Villaverde AB, Silva JA Jr, Costa MS. COX-2 mRNA expression decreases in the subplantar muscle of rat paw subjected to carrageenaninduced inflammation after low level laser therapy. Inflamm Res 2007; 56: 228-9.

Altan BA, Sokucu 0, Ozkut MM, Inan S. Metrical and histological investigation of the effects of low-level laser therapy on orthodontic tooth movement. Lasers Med Sci 2012 Jan; 27(1):131-40.

Angeletti P, Pereira MD, Gomes HC, Hino CT, Ferreira LM. Effect of low-level laser therapy (GaAlAs) on bone regeneration in midpalatal anterior suture after surgically assisted rapid maxillary expansion. Oral Surg Oral Med Oral Pathol Oral Radiol Endod. 2010;109(3):e38-46.

Artés-Ribas M, Arnabat-Dominguez J, Puigdollers A. Analgesic effect of a low-level laser therapy (830 $\mathrm{nm})$ in early orthodontic treatment. Lasers Med Sci. 2013;28(1):335-341.

Bicakci AA, Kocoglu-Altan B, Toker H, Mutaf I, Sumer Z. Efficiency of low-level laser therapy in reducing pain induced by orthodontic forces. Photomed Laser Surg. 2012;30(8):460-465.

Brown DF, Moerenhout RG. The pain experience and psychological adjustment to orthodontic treatment of preadolescents, adolescents, and adults. Am J Orthod Dentofacial Orthop. 1991; 100(4):349-356.

Cepera F, Torres FC, Scanavini MA, Paranhos LR, 
Capelozza Filho L, Cardoso MA, et al. Effect of a low-level laser on bone regeneration after rapid maxillary expansion. Am J Orthod Dentofacial Orthop. 2012;141(4):444-50.

Chow RT, David MA, Armati PJ. 830 nm laser irradiation induces varicosity formation, reduces mitochondrial membrane potential and blocks fast axonal flow in small and medium diameter rat dorsal root ganglion neurons: implications for the analgesic effects of 830 nm laser. J Peripher Nerv Syst 2007; 12: 28-39.

Çokakoglu S, Aydogan F, Aydın B. Low Level Laser Therapy in Orthodontics. Meandros Medical and Dental Journal. 2018 Aug 1;19(2):99.

Coluzzi DJ. An overview of laser wavelengths used in dentistry. Dental Clinics of North America. 2000 0ct;44(4):753-765.

Coluzzi DJ. Fundamentals of Lasers in Dentistry: Basic Science, Tissue Interactions, and Instrumentation. J Laser Dent 2008;16 (Spec issue);4-10.

Cruz DR, Kohara EK, Ribeiro MS, Wetter NU. Effects of low intensity laser therapy on the orthodontic movement velocity of human teeth: a preliminary study. Lasers Surg Med 2004; 35: 117-20.

Da Silva AP, Petri AD, Crippa GE, Stuani AS, Stuani AS, Rosa AL, et al. Effect of low-level laser therapy after rapid maxillary expansion on proliferation and differentiation of osteoblastic cells. Lasers Med Sci. 2012;27(4):777-83.

Deana NF, Zaror C, Sandoval P, Alves N. Effectiveness of low-level laser therapy in reducing orthodontic pain: a systematic review and meta-analysis. Pain Research and Management. 2017 Sep 27;2017.

Dominguez A, Velásquez SA. Effect of low-level laser therapy on pain following activation of orthodontic final archwires: a randomized controlled clinical trial. Photomed Laser Surg. 2013;31(1):36-40.

Doshi-Mehta G, Bhad-Patil WA. Efficacy of lowintensity laser therapy in reducing treatment time and orthodontic pain: a clinical investigation. Am J Orthod Dentofacial Orthop 2012; 141(3):289-97.

Escudero JSB, Perez MGB, de Oliveira Rosso MP, Buchaim DV, Pomini KT, Campos LMG, et al. Photobiomodulation therapy (PBMT) in bone repair: A systematic review.. 2019;50: 1853-1867.

Eslamian L, Borzabadi-FarahaniA,HassanzadehAzhiriA,Badiee MR, Fekrazad R The effect of 810-nm low-level laser therapy on pain caused by orthodontic elastomeric separators. Lasers Med Sci 2014; 29(2):559564.

Farias RD, Closs LQ, Miguens Jr SA. Evaluation of the use of low-level laser therapy in pain control in orthodontic patients: A randomized split-mouth clinical trial. The Angle Orthodontist. 2016 Mar;86(2):193-8. Fujiyama K, Deguchi T, Murakami T, Fujii A, Kushima $\mathrm{K}$, Takano-Yamamoto T. Clinical effect of CO (2) laser in reducing pain in orthodontics. Angle Orthod. 2008;78(2):299-303.
Goldman L, Blaney Dj, Kindel Dj Jr, Franke Ek. Effect of The Laser Beam On The Skin. Preliminary Report. J Invest Dermatol. 1963;40:121-122.

Goldman L, Gray Ja, Goldman J, Goldman B, Meyer R. Effect Of Laser Beam Impacts On Teeth. J Am Dent Assoc. 1965;70:601-606.

Goldman L, Hornby P, Meyer R, Goldman B. Impact of the laser on dental caries. Nature. 1964 Jul;203(4943):417.

Harazaki M, Isshiki Y. Soft laser irradiation effects on pain reduction in orthodontic treatment. Bull Tokyo Dent Coll. 1997;38(4):291-295.

Heidari S, Torkan S. Laser applications in orthodontics. J Lasers Med Sci. 2013;4(4):151-158.

Heravi F, Moradi A, Ahrari F. The effect of low level laser therapy on the rate of tooth movement and pain perception during canine retraction. Oral Health Dent Manag. 2014;13(2):183-188.

Huang H, Williams RC, Kyrkanides S. Accelerated orthodontic tooth movement: molecular mechanisms. Am J Orthod Dentofacial Orthop. 2014;146:620-632.

J. M. Bjordal, M. I. Johnson, V. Iversen, F. Aimbire, and R. A. B. Lopes-Martins,"Photoradiation in acute pain: A systematic review of possible mechanisms of action and clinical effects in randomized placebo-controlled trials," Photomedicine and LaserSurgery,2006; 24( 2):158-168

Kang Y, Rabie AB, Wong RW. A review of laser applications in orthodontics. Int J Orthod Milwaukee. 2014;25(1):47-56.

Kim WT, Bayome M, Park JB, Park JH, Baek SH, Kook YA. Effect of frequent laser irradiation on orthodontic pain: a single-blind randomized clinical trial. Angle Orthod. 2013;83(4):611-616.

Kravitz ND, Kusnoto B. Soft-tissue lasers in orthodontics: an overview. Am J Orthod Dentofacial Orthop. 2008;133(4 Suppl):S110-S114.

Krishnan V, Davidovitch Z. On a path to unfolding the biological mechanisms of orthodontic tooth movement. J Dent Res 2009; 88: 597-608.

Laakso EL, Cabot PJ. Nociceptive scores and endorphincontaining cells reduced by low-level laser therapy (LLLT) in inflamed paws of Wistar rat. Photomed Laser Surg 2005; 23: 32-5.

Lim HM, Lew KK, Tay DK. A clinical investigation of the efficacy of low level laser therapy in reducing orthodontic postadjustment pain. Am J Orthod Dentofacial Orthop. 1995;108(6):614-622.

Limpanichkul W, Godfrey K, Srisuk N, Rattanayatikul C. Effects of low-level laser therapy on the rate of orthodontic tooth movement. Orthodontics \& craniofacial research. 2006 Feb;9(1):38-43.

Madhavi O, Vani SK, Jayade CV, Rajani Y, Lakshmi KB, Raju KS. Influence Of Low Level Laser Therapy On Orthodontic Tooth Movement Using Apically Directed Forces. International Journal of Scientific Research. 2020 Jan 29;9(1). 
Maiman T. Stimulated Optical Radiation in Ruby. Nature 187, 493-494 (1960).

Marini I, Bartolucci ML, Bortolotti F, Innocenti G, Gatto MR, Alessandri Bonetti G. The effect of diode superpulsed low-level laser therapy on experimental orthodontic pain caused by elastomeric separators: a randomized controlled clinical trial. Lasers Med Sci. 2015;30(1):35-41.

Mistry D,Dalcy 0,Papageorgiou SN, Darendeliler MA, Papadopoulou AK. The effects of a clinically feasible application of low-level laser therapy on the rate of orthodontic tooth movement: A triple-blind, splitmouth, randomized controlled trial. Am J Orthod Dentofacial Orthop 2020 Apr; 157(4):444-453

Mizutani K, Musya Y, Wakae K, et al. A clinical study on serum prostaglandin E2 with low-level laser therapy. Photomed Laser Surg. 2004;22 (6):537-539.

Myers TD, Myers WD, Stone RM. First soft tissue study utilizing a pulsed Nd:YAG dental laser. Northwest Dent. 1989;68(2):14-17.

Nalcaci R, Cokakoglu S. Lasers in orthodontics. Eur J Dent. 2013;7(Suppl 1):S119-S125.

Parker, S. Laser-tissue interaction. Br Dent J 202, 73-81 (2007).

Qamruddin I, Alam MK, Mahroof V, Fida M, Khamis MF, Husein A. Effects of low-level laser irradiation on the rate of orthodontic tooth movement and associated pain with self-ligating brackets. Am J Orthod Dentofacial Orthop. 2017;152(5):622-630.

Ren C, McGrath C, Yang Y. The effectiveness of low-level diode laser therapy on orthodontic pain management: a systematic review and meta-analysis. Lasers Med Sci. 2015;30 (7):1881-1893.

Rodrigo Duarte Farias, Luciane Quadrado Closs, Sergio Augusto Quevedo Miguens; Evaluation of the use of low-level laser therapy in pain control in orthodontic patients: A randomized split-mouth clinical trial: Angle Orthod 2016; 86 (2): 193-198.

Sant'Anna EF, Araújo MTS, Nojima LI, Cunha ACD, Silveira BLD, Marquezan M. High-intensity laser application in Orthodontics. Dental Press J Orthod. 2017;22(6):99-109.

Shi Q, Yang S, Jia F, Xu J. Does low level laser therapy relieve the pain caused by the placement of the orthodontic separators?----a meta-analysis. Head \& face medicine. 2015 Dec 1;11(1):28.

Skondra FG, Koletsi D, Eliades T, Farmakis ET. The effect of low-level laser therapy on bone healing after rapid maxillary expansion: a systematic review. Photomedicine and laser surgery. 2018 Feb 1;36(2):6171.
Sonesson M, De Geer E, Subraian J, Petrén S. Efficacy of low-level laser therapy in accelerating tooth movement, preventing relapse and managing acute pain during orthodontic treatment in humans: a systematic review. BMC Oral Health. 2017 Dec 1;17(1):11.

Sousa MV, Scanavini MA, Sannomiya EK, Velasco LG, Angelieri F. Influence of low-level laser on the speed of orthodontic movement. Photomed Laser Surg 2011; 29: 191-6.

Sun G, Tunér J. Low-level laser therapy in dentistry. Dent Clin North Am. 2004;48(4):1061-viii

Tortamano A, Lenzi DC, Haddad AC, Bottino MC, Dominguez GC, Vigorito JW. Low-level laser therapy for pain caused by placement of the first orthodontic archwire: a randomized clinical trial. Am J Orthod Dentofacial Orthop. 2009;136 (5):662-667.

Turhani D, Scheriau M, Kapral D, Benesch T, Jonke E, Bantleon HP. Pain relief by single low-level laser irradiation in orthodontic patients undergoing fixed appliance therapy. Am J Orthod Dentofacial Orthop. 2006;130(3):371-377.

Walker JB, Buring SM. NSAID impairment of orthodontic tooth movement. Ann Pharmacother. 2001;35(1):113-115.

White JM, Gekelman D, Shin KB, Park JS, Swenson TO, Rouse BP, Tran KT, Bullard SL, Scott-Beckles LB, Oto MG, Buhler JS. Laser interaction with dental soft tissues: What do we know from our years of applied scientific research?. In Lasers in Dentistry VIII 2002 Jun 3 (Vol. 4610, pp. 39-48).

Xiaoting L, Yin T, Yangxi C. Interventions for pain during fixed orthodontic appliance therapy. A systematic review. Angle Orthod. 2010; 80(5):925-932.

Yi J, Xiao J, Li H, Li Y, Li X, Zhao Z. Effectiveness of adjunctive interventions for accelerating orthodontic tooth movement: a systematic review of systematic reviews. J Oral Rehabil. 2017;44(8):636-654

Yoshida T, Yamaguchi M, Utsunomiya T, et al. Lowenergy laser irradiation accelerates the velocity of tooth movement via stimulation of the alveolar bone remodeling. Orthod Craniofac Res. 2009;12:289-298.

Yoshida T, Yamaguchi M, Utsunomiya T, Kato M, Arai Y, Kaneda T, Yamamoto H, Kasai K. Low-energy laser irradiation accelerates the velocity of tooth movement via stimulation of the alveolar bone remodeling. Orthodontics \&t craniofacial research. 2009 Nov;12(4):289-98..

Youssef M, Ashkar S, Hamade E, Gutknecht N, Lampert F, Mir M. The effect of low-level laser therapy during orthodontic movement: a preliminary study. Lasers Med Sci 2008; 23: 27-33. 